\title{
MEV - AVAliaçÃo Morfológica do Ápice Radicular em Dentes Decíduos de Humanos, com Diferentes Graus de Patologia Pulpar e Periapical
}

Patría Motia Fentiandes 


\title{
PATRÍCIA MOTTA FERNANDES
}

\section{MEV - AVALIAÇÃO MORFOLÓGICA DO ÁPICE RADICULAR EM DENTES DECÍDUOS DE HUMANOS, COM DIFERENTES GRAUS DE PATOLOGIA PULPAR E PERIAPICAL}

\author{
Dissertação apresentada à Faculdade de Odontologia \\ de Ribeirão Preto da Universidade de São Paulo, \\ para a obtenção do título de Mestre em \\ Odontopediatria.
}

Orientadora: Profa. Dra. Léa Assed Bezerra da Silva

Ribeirão Preto-SP

2007 


\section{FICHA CATALOGRÁFICA}

Fernandes, Patrícia Motta

MEV - Avaliação morfológica do ápice radicular em dentes decíduos de humanos, com diferentes graus de patologia pulpar e periapical. Ribeirão Preto, 2007.

50 p. : il. ; $30 \mathrm{~cm}$

Dissertação de Mestrado, apresentada à Faculdade de Odontologia de Ribeirão Preto/USP. Área de concentração: Odontopediatria.

Orientadora: Silva, Léa Assed Bezerra.

1. Dentes decíduos 2. Alterações morfológicas apicais.

3. Microscopia Eletrônica de Varredura. 4. Lesão periapical. 


\section{MEV - AVALIAÇÃO MORFOLÓGICA DO ÁPICE RADICULAR EM DENTES DECÍDUOS DE HUMANOS, COM DIFERENTES GRAUS DE PATOLOGIA \\ PULPAR E PERIAPICAL}

Dissertação apresentada à Faculdade de Odontologia de Ribeirão Preto da Universidade de São Paulo, para a obtenção do Título de Mestre em Odontopediatria.

Aprovado em:

Banca Examinadora

Prof. Dr

Instituição: Assinatura:

Prof. Dr.

Instituição: Assinatura:

Prof. Dr. Instituição: Assinatura: 


\section{DADOS CURRICULARES}

\section{PATRÍCIA MOTTA FERNANDES}

Nascimento 07 de março de 1979 - Campo Grande/MS

Filiação Antônio Fernandes

Vitoriana Motta Fernandes

1999-2003 Graduação em Odontologia

Universidade para o Desenvolvimento do Estado e da Região do Pantanal - UNIDERP

2005-2007 Especialização em Odontopediatria

Associação Odontológica de Ribeirão Preto - AORP

2006 Curso de Aperfeiçoamento no Atendimento Odontológico a Pacientes Especiais.

Faculdade de Odontologia de Ribeirão Preto - USP

2006 Curso de Aperfeiçoamento no Atendimento Odontológico a Bebês Normais e Especiais.

Faculdade de Odontologia de Ribeirão Preto - USP

2005 - 2007 Curso de Pós-Graduação (Mestrado) em Odontologia

Área de concentração: Odontopediatria

Faculdade de Odontologia de Ribeirão Preto - USP 
"De tudo, ficaram três coisas:

A certeza de que estamos sempre começando...

A certeza de que é preciso continuar...

A certeza de que seremos interrompidos antes de terminar...

Portanto devemos:

Fazer da interrup̧ão um caminho novo...

Da queda, um passo da dança...

Do medo, uma escada...

Do sonho uma ponte...

Da procura, um encontro..." 


\section{DEDICATÓRIA}

A Deus. Em momentos difíceis, quando alguns obstáculos pareciam intransponiveis e os sonhos distantes e quase impossíveis, foi acreditando em sua existência que consegui prosseguir.

Aos meus pais, Antônio Fernandes e Vitoriana Motta Fernandes, por me guiarem, sempre com muito amor, a escolher os caminhos para a realização de minhas conquistas, principalmente com responsabilidade e honestidade. Apesar de alguns obstáculos aparentemente intransponíveis, vocês sempre me apoiaram, sem medir esforços para a realização dos meus sonhos.

Obrigada pelo amor, compreensão e por me ensinarem que os sonhos valem a pena e que devemos lutar para sermos felizes. A vocês não dedico esta conquista, mas todas as conquistas da minha vida. Vocês são tudo para mim.

Aos meus irmãos, Aluísio e Adriana, pela amizade, compreensão, carinho, proteção, companheirismo e apoio durante todos os momentos de minha vida. 


\section{AGRADECIMENTOS ESPECIAIS}

À minha orientadora, Profa. Dra. Léa Assed Bezerra da silva. Exemplo de determinação e amor à profissão. Sou grata pela sua orientação, imprescindivel na minha formação profissional. Seus conhecimentos e sua dedicação me guiaram e me motivaram a cada instante nessa trajetória. Agradeço pelos seus ensinamentos, colaboração constante e pela atenção durante esta caminhada. Saiba que é uma pessoa iluminada e agradeço a Deus por colocá-la em meu caminho. Obrigada por tudo.

Ao Prof. Dr. Marcos Antonio Rossi, da Faculdade de Medicina de Ribeirão Preto - USP, pela fundamental colaboração na realização da parte experimental desse trabalho.

Ao Prof. Dr. Mário Roberto Leonardo, pelo seu incontestável profissionalismo, competência e amor à Endodontia. Obrigada por todo o conhecimento transmitido durante esta trajetória.

Ao Dr. Lenaldo Branco Rocha, da Faculdade de Medicina de Ribeirão Preto USP, os meus sinceros agradecimentos pela atenção e disponibilidade durante a realização deste trabalho e pela incansável colaboração na avaliação dos espécimes.

Ao Prof. Dr. Paulo Nelson Filho. Obrigada pela dedicação, apoio e estímulo constante durante minha trajetória no curso de Pós-graduação e por compartilhar comigo o seu valioso conhecimento científico e profissional. Seus ensinamentos serão sempre lembrados por mim. Agradeço por tudo. 


\section{AGRADECIMENTOS}

À Faculdade de Odontologia de Ribeirão Preto da Universidade de São Paulo, na pessoa de sua diretora, Prof. Dra. Marisa Semprini e da Vice-Diretora Profa. Dra. Sada Assed.

À Coordenação do Programa de Pós-Graduação em Odontopediatria da Faculdade de Odontologia de Ribeirão Preto da Universidade de São Paulo, na pessoa da coordenadora Profa. Dra. Léa Assed Bezerra da Silva e do Vice-Coordenador Prof. Dr. Paulo Nelson Filho, pela oportunidade de enriquecer a minha carreira profissional neste conceituado Programa de Pós-graduação.

Aos docentes do Departamento de Clínica Infantil, Odontologia Preventiva e Social da Faculdade de Odontologia de Ribeirão Preto-USP, Prof. Dr. Adilson Thomazinho, Profa. Dra. Aldevina Campos de Freitas, Prof. Dr. José Tarcísio Lima Ferreira, Profa. Dra. Kranya Victória Díaz Serrano, Profa. Dra. Léa Assed Bezerra da Silva, Profa. Dra. Sada Assed, Prof. Dr. Mário Roberto Leonardo, Profa. Dra. Maria Bernadete Sasso Stuani, Profa. Dra. Maria Conceição Pereira Saraiva, Profa. Dra. Maria Cristina Borsatto, Profa. Dra. Mirian Aiko Nakane Matsumoto e Profa. Alexandra Mussolino de Queiroz pelo carinho e atenção com que me acolheram e por todos os conhecimentos que enriqueceram minha carreira profissional.

À professora Alexandra Mussolino de Queiroz, e às amigas Carolina Paes Torres, Gisele Faria e Raquel Assed Bezerra da Silva, pelo carinho, dedicação e por todos os conhecimentos transmitidos que enriqueceram minha vida profissional.

Às funcionárias do Departamento de Patologia da Faculdade de Medicina de Ribeirão Preto - USP, Mônica Azevedo de Abreu e Ligia Baroza Santoro, pela atenção e disposição na execução da parte experimental deste trabalho. 
Aos funcionários do Departamento de Clínica Infantil, Odontologia Preventiva e Social da Faculdade de Odontologia de Ribeirão Preto da Universidade de São Paulo, Fátima Aparecida Jacinto Daniel, Marco Antônio dos Santos, Nilva Aparecida Afonso Ruggiero, Cleber Barbosa Rita, Vera Ribeiro do Nascimento, José Aparecido Neves do Nascimento e Carmo Euripedes Terra Barreto, pelo carinho e por toda atenção dispensada.

Aos funcionários do "Centro de Formação de Recursos Humanos Especializados no Atendimento Odontológico de Pacientes Especiais", Benedita Viana Rodrigues, Fătima Rizóli, Nadir Felício e Renata Aparecida Fernandes Rodrigues pelo carinho e alegre convivência.

Á secretária Rejane Gomes Cavalheiro de Mazer, pela atenção dispensada em todos os momentos.

Às funcionárias da Seção de Pós-Graduação da Faculdade de Odontologia de Ribeirão Preto da Universidade de São Paulo, Isabel Cristina Galino Sola e Regiane Cristina Moi Sacilloto pela cordialidade e atenção.

Às colegas do curso mestrado Carolina Guerra, Cristiane Tomaz Rocha, Christiane Ristum Bagatin, Iza Peixoto, Jaciara Miranda Gomes da Silva, Maria Stella Gaspar Gomes Raffaini, Patricia Monteiro, Regina Aparecida Segatto Saiani, Soraya Cheier Dib Gonçalves e Thaís Andreoli do Amaral, pela agradável convivência.

Aos alunos do doutorado Francisco Wanderley Garcia de Paula e Silva, Alexandra Mussolino de Queiroz, Raquel Assed Bezerra da Silva, Soraia Monique Fioratti Aguiar, Marta Estela Saravia, Valéria Pontelli Navarro, Sara Elisa Matar e Maria Angélica Hueb, pela troca de experiências e convivência agradável. 
A Coordenação do Curso de Odontologia da Universidade para o Desenvolvimento do Estado e da Região do Pantanal - UNIDERP, na pessoa da Professora Rozana Beatriz Franco Baccaro. Obrigada a todos os professores por todos os ensinamentos transmitidos durante meu curso de graduação.

Às Professoras da Disciplina de Odontopediatria e Ortodontia Preventiva e Disciplina de Pacientes Especiais da UNIDERP, Ana Paula Souza Pinto, Catarina Prado, Mônica Aratani, Gysélle Saddi Tannous, Raquel Trombini Pertinhes Macerou e Renata Santos Belchior. Agradeço pela dedicação e ensinamentos permanentes e pelo incentivo durante a graduação. Por acreditarem na minha capacidade e na vontade de seguir adiante nessa trajetória. A cada momento, mesmo distante, me apoiaram e estimularam. Espero retribuir a todas vocês o carinho que me ofereceram nesse periodo. Essa conquista também foi possível graças ao apoio e incentivo desde os primeiros passos da minha carreira profissional, e por sempre me incentivarem na busca desse sonho, independente dos obstáculos.

\section{À Associą̧ão Brasileira de Odontologia - Seção de Mato Grosso do Sul, por} todo o apoio e incentivo durante esta caminhada.

Aos meus tios Clăudio dos Reis Ferreira e Maria Cicera Motta Ferreira, agradeço a tudo que fizeram por mim nesse período. Obrigada pelo amor, carinho e preocupação durante a minha estada em Ribeirão Preto.

Aos meus queridos amigos, Andréia lafar e Henrique Jafar, pelo carinho e apoio durante esta caminhada.

À grande amiga Cristiane Tomaz Rocha, por compartilhar os momentos de alegria e de saudades de nossos familiares. Saiba que você foi uma grande irmã que conquistei durante este período. Amiga que me apoiou em momentos dificeis quando precisei, sempre disposta a ajudar. Obrigada pelos conselhos, conversas e risadas. "Uma amizade para sempre". 
À amiga Ivna Fernandes Queiroz, exemplo de determinação e responsabilidade. Agradeço pela sua amizade e pelo constante apoio.

Ao Júlio César de Matos, pela atenção durante a diagramação e impressão deste trabalho.

À CAPES, pelo auxílio financeiro.

A todas as pessoas que, direta ou indiretamente, contribuíram para a realização deste trabalho. 


\section{MEV - AVALIAÇÃO MORFOLÓGICA DO ÁPICE RADICULAR EM DENTES DECÍDUOS DE HUMANOS, COM DIFERENTES GRAUS DE PATOLOGIA \\ PULPAR E PERIAPICAL}

Dissertação apresentada à Faculdade de Odontologia de Ribeirão Preto da Universidade de São Paulo, para a obtenção do Título de Mestre em Odontopediatria.

Aprovado em:

Banca Examinadora

Prof. Dr

Instituição: Assinatura:

Prof. Dr.

Instituição: Assinatura:

Prof. Dr. Instituição: Assinatura: 


\section{DADOS CURRICULARES}

\section{PATRÍCIA MOTTA FERNANDES}

Nascimento 07 de março de 1979 - Campo Grande/MS

Filiação Antônio Fernandes

Vitoriana Motta Fernandes

1999-2003 Graduação em Odontologia

Universidade para o Desenvolvimento do Estado e da Região do Pantanal - UNIDERP

2005-2007 Especialização em Odontopediatria

Associação Odontológica de Ribeirão Preto - AORP

2006 Curso de Aperfeiçoamento no Atendimento Odontológico a Pacientes Especiais.

Faculdade de Odontologia de Ribeirão Preto - USP

2006 Curso de Aperfeiçoamento no Atendimento Odontológico a Bebês Normais e Especiais.

Faculdade de Odontologia de Ribeirão Preto - USP

2005 - 2007 Curso de Pós-Graduação (Mestrado) em Odontologia

Área de concentração: Odontopediatria

Faculdade de Odontologia de Ribeirão Preto - USP 
"De tudo, ficaram três coisas:

A certeza de que estamos sempre começando...

A certeza de que é preciso continuar...

A certeza de que seremos interrompidos antes de terminar...

Portanto devemos:

Fazer da interrup̧ão um caminho novo...

Da queda, um passo da dança...

Do medo, uma escada...

Do sonho uma ponte...

Da procura, um encontro..." 


\section{DEDICATÓRIA}

A Deus. Em momentos difíceis, quando alguns obstáculos pareciam intransponiveis e os sonhos distantes e quase impossíveis, foi acreditando em sua existência que consegui prosseguir.

Aos meus pais, Antônio Fernandes e Vitoriana Motta Fernandes, por me guiarem, sempre com muito amor, a escolher os caminhos para a realização de minhas conquistas, principalmente com responsabilidade e honestidade. Apesar de alguns obstáculos aparentemente intransponíveis, vocês sempre me apoiaram, sem medir esforços para a realização dos meus sonhos.

Obrigada pelo amor, compreensão e por me ensinarem que os sonhos valem a pena e que devemos lutar para sermos felizes. A vocês não dedico esta conquista, mas todas as conquistas da minha vida. Vocês são tudo para mim.

Aos meus irmãos, Aluísio e Adriana, pela amizade, compreensão, carinho, proteção, companheirismo e apoio durante todos os momentos de minha vida. 


\section{AGRADECIMENTOS ESPECIAIS}

À minha orientadora, Profa. Dra. Léa Assed Bezerra da silva. Exemplo de determinação e amor à profissão. Sou grata pela sua orientação, imprescindivel na minha formação profissional. Seus conhecimentos e sua dedicação me guiaram e me motivaram a cada instante nessa trajetória. Agradeço pelos seus ensinamentos, colaboração constante e pela atenção durante esta caminhada. Saiba que é uma pessoa iluminada e agradeço a Deus por colocá-la em meu caminho. Obrigada por tudo.

Ao Prof. Dr. Marcos Antonio Rossi, da Faculdade de Medicina de Ribeirão Preto - USP, pela fundamental colaboração na realização da parte experimental desse trabalho.

Ao Prof. Dr. Mário Roberto Leonardo, pelo seu incontestável profissionalismo, competência e amor à Endodontia. Obrigada por todo o conhecimento transmitido durante esta trajetória.

Ao Dr. Lenaldo Branco Rocha, da Faculdade de Medicina de Ribeirão Preto USP, os meus sinceros agradecimentos pela atenção e disponibilidade durante a realização deste trabalho e pela incansável colaboração na avaliação dos espécimes.

Ao Prof. Dr. Paulo Nelson Filho. Obrigada pela dedicação, apoio e estímulo constante durante minha trajetória no curso de Pós-graduação e por compartilhar comigo o seu valioso conhecimento científico e profissional. Seus ensinamentos serão sempre lembrados por mim. Agradeço por tudo. 


\section{AGRADECIMENTOS}

À Faculdade de Odontologia de Ribeirão Preto da Universidade de São Paulo, na pessoa de sua diretora, Prof. Dra. Marisa Semprini e da Vice-Diretora Profa. Dra. Sada Assed.

À Coordenação do Programa de Pós-Graduação em Odontopediatria da Faculdade de Odontologia de Ribeirão Preto da Universidade de São Paulo, na pessoa da coordenadora Profa. Dra. Léa Assed Bezerra da Silva e do Vice-Coordenador Prof. Dr. Paulo Nelson Filho, pela oportunidade de enriquecer a minha carreira profissional neste conceituado Programa de Pós-graduação.

Aos docentes do Departamento de Clínica Infantil, Odontologia Preventiva e Social da Faculdade de Odontologia de Ribeirão Preto-USP, Prof. Dr. Adilson Thomazinho, Profa. Dra. Aldevina Campos de Freitas, Prof. Dr. José Tarcísio Lima Ferreira, Profa. Dra. Kranya Victória Díaz Serrano, Profa. Dra. Léa Assed Bezerra da Silva, Profa. Dra. Sada Assed, Prof. Dr. Mário Roberto Leonardo, Profa. Dra. Maria Bernadete Sasso Stuani, Profa. Dra. Maria Conceição Pereira Saraiva, Profa. Dra. Maria Cristina Borsatto, Profa. Dra. Mirian Aiko Nakane Matsumoto e Profa. Alexandra Mussolino de Queiroz pelo carinho e atenção com que me acolheram e por todos os conhecimentos que enriqueceram minha carreira profissional.

À professora Alexandra Mussolino de Queiroz, e às amigas Carolina Paes Torres, Gisele Faria e Raquel Assed Bezerra da Silva, pelo carinho, dedicação e por todos os conhecimentos transmitidos que enriqueceram minha vida profissional.

Às funcionárias do Departamento de Patologia da Faculdade de Medicina de Ribeirão Preto - USP, Mônica Azevedo de Abreu e Ligia Baroza Santoro, pela atenção e disposição na execução da parte experimental deste trabalho. 
Aos funcionários do Departamento de Clínica Infantil, Odontologia Preventiva e Social da Faculdade de Odontologia de Ribeirão Preto da Universidade de São Paulo, Fátima Aparecida Jacinto Daniel, Marco Antônio dos Santos, Nilva Aparecida Afonso Ruggiero, Cleber Barbosa Rita, Vera Ribeiro do Nascimento, José Aparecido Neves do Nascimento e Carmo Euripedes Terra Barreto, pelo carinho e por toda atenção dispensada.

Aos funcionários do "Centro de Formação de Recursos Humanos Especializados no Atendimento Odontológico de Pacientes Especiais", Benedita Viana Rodrigues, Fătima Rizóli, Nadir Felício e Renata Aparecida Fernandes Rodrigues pelo carinho e alegre convivência.

Á secretária Rejane Gomes Cavalheiro de Mazer, pela atenção dispensada em todos os momentos.

Às funcionárias da Seção de Pós-Graduação da Faculdade de Odontologia de Ribeirão Preto da Universidade de São Paulo, Isabel Cristina Galino Sola e Regiane Cristina Moi Sacilloto pela cordialidade e atenção.

Às colegas do curso mestrado Carolina Guerra, Cristiane Tomaz Rocha, Christiane Ristum Bagatin, Iza Peixoto, Jaciara Miranda Gomes da Silva, Maria Stella Gaspar Gomes Raffaini, Patricia Monteiro, Regina Aparecida Segatto Saiani, Soraya Cheier Dib Gonçalves e Thaís Andreoli do Amaral, pela agradável convivência.

Aos alunos do doutorado Francisco Wanderley Garcia de Paula e Silva, Alexandra Mussolino de Queiroz, Raquel Assed Bezerra da Silva, Soraia Monique Fioratti Aguiar, Marta Estela Saravia, Valéria Pontelli Navarro, Sara Elisa Matar e Maria Angélica Hueb, pela troca de experiências e convivência agradável. 
A Coordenação do Curso de Odontologia da Universidade para o Desenvolvimento do Estado e da Região do Pantanal - UNIDERP, na pessoa da Professora Rozana Beatriz Franco Baccaro. Obrigada a todos os professores por todos os ensinamentos transmitidos durante meu curso de graduação.

Às Professoras da Disciplina de Odontopediatria e Ortodontia Preventiva e Disciplina de Pacientes Especiais da UNIDERP, Ana Paula Souza Pinto, Catarina Prado, Mônica Aratani, Gysélle Saddi Tannous, Raquel Trombini Pertinhes Macerou e Renata Santos Belchior. Agradeço pela dedicação e ensinamentos permanentes e pelo incentivo durante a graduação. Por acreditarem na minha capacidade e na vontade de seguir adiante nessa trajetória. A cada momento, mesmo distante, me apoiaram e estimularam. Espero retribuir a todas vocês o carinho que me ofereceram nesse periodo. Essa conquista também foi possível graças ao apoio e incentivo desde os primeiros passos da minha carreira profissional, e por sempre me incentivarem na busca desse sonho, independente dos obstáculos.

\section{À Associą̧ão Brasileira de Odontologia - Seção de Mato Grosso do Sul, por} todo o apoio e incentivo durante esta caminhada.

Aos meus tios Clăudio dos Reis Ferreira e Maria Cicera Motta Ferreira, agradeço a tudo que fizeram por mim nesse período. Obrigada pelo amor, carinho e preocupação durante a minha estada em Ribeirão Preto.

Aos meus queridos amigos, Andréia lafar e Henrique Jafar, pelo carinho e apoio durante esta caminhada.

À grande amiga Cristiane Tomaz Rocha, por compartilhar os momentos de alegria e de saudades de nossos familiares. Saiba que você foi uma grande irmã que conquistei durante este período. Amiga que me apoiou em momentos dificeis quando precisei, sempre disposta a ajudar. Obrigada pelos conselhos, conversas e risadas. "Uma amizade para sempre". 
À amiga Ivna Fernandes Queiroz, exemplo de determinação e responsabilidade. Agradeço pela sua amizade e pelo constante apoio.

Ao Júlio César de Matos, pela atenção durante a diagramação e impressão deste trabalho.

À CAPES, pelo auxílio financeiro.

A todas as pessoas que, direta ou indiretamente, contribuíram para a realização deste trabalho. 


\section{Resumo}

FERNANDES, PM. MEV - Avaliação morfológica do ápice radicular em dentes decíduos de humanos, com diferentes graus de patologia pulpar e periapical. Ribeirão Preto, 2007. 50 p. Dissertação [mestrado] - Faculdade de Odontologia de Ribeirão Preto, Universidade de São Paulo.

O objetivo deste estudo foi avaliar a morfologia da superfície externa de ápices radiculares de dentes decíduos de humanos com necrose pulpar, com e sem lesão periapical visível radiograficamente, e de dentes com vitalidade pulpar, por meio da microscopia eletrônica de varredura (MEV). Dezenove dentes foram extraídos sendo cinco dentes com vitalidade pulpar (Grupo I), seis com necrose pulpar sem lesão periapical (Grupo II) e oito com necrose pulpar e lesão periapical (Grupo III). Os dentes (incisivos e molares) foram lavados com solução salina e imersos em solução de tripsina $0,03 \mathrm{~g} / \mathrm{mL}$ por 20 minutos. Decorrido esse período, os dentes foram lavados com solução tampão de cacodilato de sódio 0,1M e armazenados em solução de Karnovsky modificada. Após 5 dias, os ápices radiculares foram seccionados, desidratados em série crescente de etanol, submetidos à secagem pelo método do ponto crítico com dióxido de carbono, fixados em "stubs" e metalizados com ouro puro para análise em MEV. A superfície do ápice radicular foi avaliada com relação à presença de fibras e áreas de reabsorção dentinária e cementária. $\mathrm{Na}$ superfície radicular apical dos dentes com vitalidade pulpar e com necrose pulpar sem lesão periapical foi observada a presença de fibras e ausência de reabsorção em todos os casos (100\%). Por outro lado, todos os espécimes (100\%) com necrose pulpar e presença de lesão periapical apresentaram ausência total de fibras e áreas de reabsorção cementária. Áreas de reabsorção dentinária foram observadas em 2 espécimes. Os resultados obtidos demonstraram a presença de diferenças morfológicas na região apical de dentes decíduos com diferentes graus de patologia pulpar e periapical. A presença de áreas de reabsorção cementária e ausência de fibras nos dentes decíduos com lesão periapical indicam a necessidade da aplicação de medidas terapêuticas específicas.

Palavras-chave: dentes decíduos; alterações morfológicas apicais; microscopia eletrônica de varredura; lesão periapical 


\section{Abstract}

FERNANDES, PM. SEM - Morphological evaluation of the root apex in human primary teeth with different degrees of pulpal and periapical pathology. Ribeirão Preto, 2007. 50 p. Dissertação [mestrado] - Faculdade de Odontologia de Ribeirão Preto, Universidade de São Paulo.

The objective of this study was to evaluate, by scanning electron microscopy (SEM), the morphology of the outer surface of root apexes of human primary teeth with pulp vitality and teeth with pulp necrosis, with and without radiographically visible periapical lesion. Nineteen teeth were extracted, being five teeth with pulp vitality (Group I), six with pulp necrosis without periapical lesion (Group II) and eight with pulp necrosis and periapical lesion (Group III). The teeth (incisors and molars) were washed in saline and immersed in $0.03 \mathrm{~g} / \mathrm{mL}$ trypsin solution during 20 minutes. After this period, the teeth were washed in $0.1 \mathrm{M}$ sodium cacodylate buffer solution and stored in modified Karnovsky's solution. After 5 days, the root apexes were sectioned, dehydrated in an ascending ethanol series, critical-point dried with $\mathrm{CO}_{2}$, mounted on stubs, and sputter-coated with gold for SEM analysis. The root apex surface was examined with respect to the presence of fibers and areas of dentinal and cemental resorption. In the apical root surface of the teeth with pulp vitality and teeth with pulp necrosis without periapical lesion presence of fibers and absence of resorption were observed in all cases (100\%). On the other hand, all specimens $(100 \%)$ with pulp necrosis and periapical lesion showed total absence of fibers and areas of cemental resorption. The results of this study demonstrated the existence of morphological differences in the apical region of primary teeth with different degrees of pulpal and periapical pathology. The presence of areas of cemental resorption and absence of fibers in the primary teeth with periapical lesion indicate the need for application of specific therapeutic measures.

Key words: primary teeth; apical morphological alterations; scanning electron microscopy; periapical lesion 


\section{SUMÁRIO}

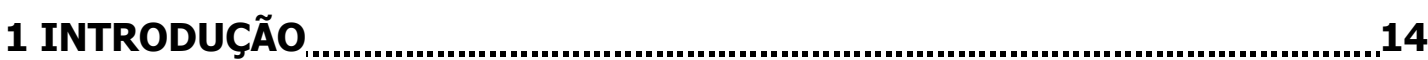

2 PROPOSIÇÃO

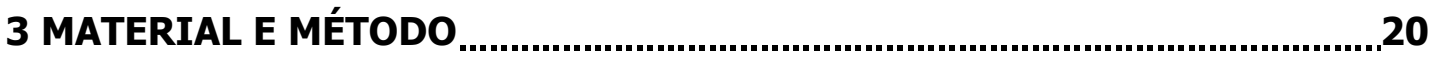

3.1 Seleção da amostras......................................................................21

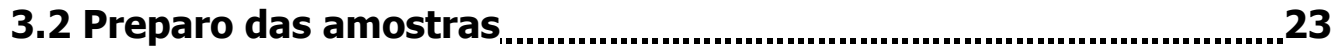

3.3 Processamento para Microscopia Eletrônica de Varredura...........26

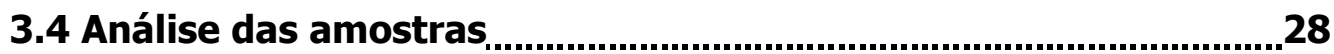

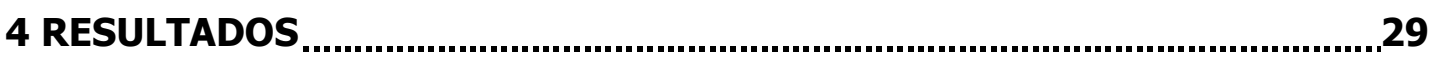

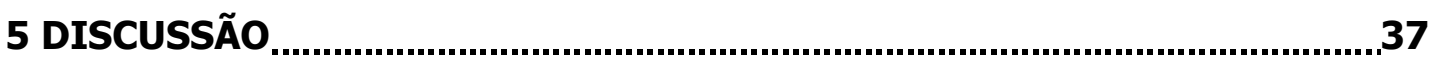

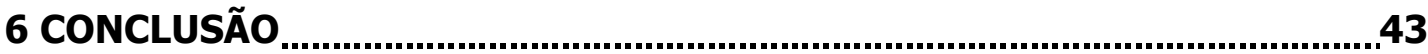

REFERÊNCIAS

ANEXO 
1 Introdução 


\section{INTRODUÇÃo}

Morfologicamente os dentes decíduos, após a formação de esmalte e dentina determinando a junção amelocementária, iniciam o seu desenvolvimento radicular. Após o término da formação radicular ocorre a deposição de cemento, que é um tecido mineralizado que recobre as raízes dos dentes de humanos (Bhaskar, 1989; Bilgin et al., 2004). A formação deste tecido inicia-se na região cervical do dente, na junção amelocementária, e termina junto ao ápice radicular (Bhaskar, 1989; Cholia et al., 2005), atuando como um meio para a ancoragem das fibras colágenas que ligam o elemento dental às estruturas vizinhas, servindo como proteção às estruturas envolvidas (Bhaskar, 1989).

A ocorrência de reabsorção radicular apical fisiológica por clastos é uma característica de dentes decíduos de humanos (Yawaka et al., 2003). Trata-se de uma condição que resulta na perda de tecidos mineralizados, que incluem a dentina e o cemento (Tronstad, 1988), frequentemente presente durante o processo de erupção do dente sucessor permanente (Yawaka et al., 2003).

No entanto, reabsorções radiculares patológicas podem também ocorrer em dentes decíduos, devido à infecção por microrganismos, trauma dental ou força ortodôntica excessiva (Laux et al., 2000; Faltin et al., 2001; Fuss et al., 2003). Segundo Consolaro (2005), a reabsorção radicular externa patológica pode ter seu início em qualquer região da superfície radicular e, dependendo da etiologia, essa reabsorção pode comprometer a estrutura dental gradativamente, seguindo um sentido aleatório e irregular, com alterações morfológicas possíveis de serem observadas, inclusive, por meio da microscopia eletrônica de varredura. 
A reabsorção radicular patológica de origem bacteriana ocorre devido à presença de infecção nos tecidos pulpares e periapicais por microrganismos (Assed, 2005), presentes inicialmente na luz do canal radicular e, posteriormente, disseminados por todo o sistema de canais radiculares (túbulos dentinários, canais laterais, canais acessórios, canais secundários e superfície do cemento radicular apical), atingindo os tecidos periapicais, com ocorrência de reabsorção óssea e instalação da lesão periapical (Leonardo et al., 2002; Fuss et al., 2003; Leonardo, 2005) e infecção extra-radicular, como relatado por Tronstad et al. (1987, 1990). Assim, a superfície externa do ápice radicular de dentes com necrose pulpar e lesão periapical visível radiograficamente pode apresentar áreas de reabsorção de cemento e dentina, as quais podem favorecer a retenção e a colonização por microrganismos (Tronstad et al., 1987).

Para melhor visualização dessas alterações, a microscopia eletrônica de varredura (MEV) vem sendo utilizada para avaliar a presença ou ausência de microrganismos no sistema de canais radiculares, na superfície externa do ápice radicular e na região periapical de dentes permanentes (Molven et al., 1991; Morfis et al., 1992; Perez et al., 1993; Calas et al., 1994; Sen et al., 1995; Lomçali et al., 1996; Sen et al., 1997; Gutiérrez et al., 1999; Leonardo et al., 2002; Lyroudia et al., 2002), sendo um importante método para o estudo das patologias periapicais permitindo avaliar, também, a topografia do ápice radicular (Fellini Filho, 1999; Leonardo et al., 2002). Esse conhecimento tem servido como base para a implementação de materiais e de técnicas de tratamento endodôntico, que diferem em função dos diferentes graus de patologia pulpar e periapical, contribuindo para a elevação dos índices de sucesso pós-tratamento endodôntico de dentes permanentes. 
Em 2002, Leonardo et al. avaliaram, em MEV, as alterações morfológicas e a presença de microrganismos na região do ápice radicular de dentes permanentes, observando que a completa destruição das fibras colágenas e a presença de microrganismos sob a forma de biofilme ocorreu apenas nos dentes com necrose pulpar e lesão periapical

No entanto, não há estudos publicados avaliando as alterações morfológicas ocorridas na região apical de dentes decíduos, com e sem alteração pulpar e periapical. 
2 Proposição 


\section{Proposição}

O objetivo deste estudo foi avaliar em Microscopia Eletrônica de Varredura (MEV), ápices radiculares de dentes decíduos extraídos de humanos, com relação à presença de fibras e áreas de reabsorção radicular apical na superfície externa (cemento e dentina), nas seguintes situações:

dentes portadores de vitalidade pulpar;

dentes portadores de necrose pulpar, sem lesão periapical visível radiograficamente; e

dentes portadores de necrose pulpar, com lesão periapical crônica visível radiograficamente. 
3 Materiale Método 


\section{Material e Método}

\subsection{Seleção das Amostras}

O presente trabalho foi submetido à apreciação pelo Comitê de Ética em Pesquisa envolvendo seres humanos da Faculdade de Odontologia de Ribeirão Preto da Universidade de São Paulo (processo no 2006.1.1310.58.2), tendo sido aprovado (Anexo A).

Participaram da pesquisa pacientes de ambos os sexos, com faixa etária entre 4 e 8 anos de idade, com boa saúde geral, que compareceram à Clínica de Odontopediatria do Departamento de Clínica Infantil, Odontologia Preventiva e Social da Faculdade de Odontologia de Ribeirão Preto-USP, para tratamento odontológico, e que não tinham sido submetidos à antibioticoterapia há pelo menos 3 meses.

Os responsáveis pelos pacientes foram informados a respeito do estudo e assinaram um termo de consentimento livre e esclarecido, confirmando a participação de seus filhos na pesquisa.

Dentes decíduos com indicação de exodontia (incisivos centrais e laterais, primeiros e segundos molares, superiores e inferiores), sem nenhum tratamento prévio, com coroa extensamente destruída em função da cárie dental, sem a possibilidade de tratamento restaurador ou dentes hígidos com retenção prolongada na cavidade bucal foram incluídos no estudo. Para a seleção dos dentes, foi realizada a anamnese, exame clínico e exame radiográfico, tendo como base a ficha da disciplina de Odontopediatria da Faculdade de Odontologia de Ribeirão Preto-USP. 
Foram selecionados dentes com necrose pulpar, sem e com lesão periapical visível radiograficamente, que apresentavam exposição pulpar por cárie, presença ou ausência de fístula e menos de $2 / 3$ de rizólise. Também, os dentes não poderiam apresentar profundidade de sondagem periodontal superior a $3 \mathrm{~mm}$. Ao exame radiográfico periapical, nos dentes portadores de lesão deveriam ser observadas áreas radiolúcidas definidas na região periapical (lesão periapical crônica).

Os dentes com vitalidade pulpar, comprovada após testes de sensibilidade, apresentaram coroa íntegra e raízes com menos de 2/3 de rizólise, ausência de mobilidade, ausência de fístula, profundidade de sondagem periodontal menor que $3 \mathrm{~mm}$, espaço do ligamento periodontal normal e integridade da lâmina dura.

Para a realização do exame radiográfico, foram utilizados filmes periapicais Ultraspeed (Eastman Kodak Comp. - Rochester - NY - USA) de tamanho 0 ou 2, conforme a idade da criança, e aparelho de Rx (Dabi Atlante, Ribeirão Preto, SP) com 70KVp e 10mA. O tempo de exposição utilizado foi de 0,6 segundos. As radiografias foram reveladas e arquivadas em cartelas plásticas.

Após a anti-sepsia da cavidade bucal com 10,0 mL de solução de gluconato de clorexidina a 0,12\% (Periogard - Colgate/Palmolive Ind. Brasileira Osasco - SP), sob a forma de bochecho por 1 minuto, foi realizada a anestesia local com Mepivacaína a 2\% (DFL Ind. e Comércio Ltda - Rio de Janeiro). A seguir, foi efetuado o descolamento dos dentes com espátula 7 ou Hollenback, luxação e extração com elevadores ou fórceps. Na dependência da necessidade, a região foi ou não suturada. 
A tabela 1 apresenta a distribuição dos diferentes grupos experimentais e o número de amostras.

Tabela 1 - Distribuição dos grupos experimentais

\begin{tabular}{clc}
\hline Grupos & \multicolumn{1}{c}{ Diagnóstico } & Número de Amostras \\
\hline I & $\begin{array}{l}\text { Dentes decíduos portadores de vitalidade pulpar } \\
\text { II }\end{array}$ & $\begin{array}{l}\text { Dentes decíduos portadores de necrose pulpar sem } \\
\text { lesão periapical visível radiograficamente }\end{array}$ \\
& $\begin{array}{l}\text { Dentes decíduos portadores de necrose pulpar e } \\
\text { nítida lesão periapical visível radiograficamente }\end{array}$ & 6 \\
\hline
\end{tabular}

\subsection{Preparo das Amostras}

Após a obtenção dos espécimes, as superfícies radiculares foram cuidadosamente lavadas com solução de cloreto de sódio a 0,9\% esterilizada. Cuidados foram tomados com o objetivo de não ocasionar danos à superfície radicular. Nos casos onde havia lesão periapical aderida à superfície radicular, a mesma foi removida com auxílio de lâmina de bisturí, com o cuidado de não afetar a superfície radicular.

Em seguida, os dentes foram colocados, durante 20 minutos, em recipientes de vidro esterilizados contendo 0,15g de tripsina (tipo T7409 de $10 \mathrm{~g}$, Sigma-Aldrich Co., St. Louis, MO) (Figura 1A), pesada em balança eletrônica de alta precisão (Bioprecisa FA2104N, Curitiba, PR, Brasil) (Figura 1B) e diluída em 5,0mL de água destilada, obtendo-se uma concentração de 0,03g/mL (Figura 1C). Posteriormente, os dentes foram lavados em solução tampão de cacodilato de sódio 0,1M (Figura 1D) e colocados em recipientes individualizados contendo solução de Karnovsky modificada (glutaraldeído a 8\%, paraformaldeído a 12\%, 
cacodilato de sódio $0,2 \mathrm{M}$ pH 7,2-7,4) para fixação, por um período mínimo de 5 dias (Figura 1E).

Decorrido esse período, com o auxílio de um disco de carburundum acionado em baixa rotação, foi efetuado um sulco perpendicular ao sentido do longo eixo da raiz, a uma distância de 3mm do ápice radicular (Figura 1F), o qual serviu de guia para a introdução de um cinzel cirúrgico que, com o auxílio de um martelo cirúrgico, promoveu a secção do remanescente radicular, destacando-se a porção apical. Essas manobras foram efetuadas em câmara de fluxo laminar, com o cuidado de não afetar a porção radicular apical.

No caso dos molares, a raiz menos acometida pelo processo de rizólise foi escolhida para análise, satisfazendo os critérios de inclusão previamente estabelecidos. 
Figura 1 - Preparo dos dentes

A. Frasco de tripsina (Sigma-Aldrich).

B. Balança de alta precisão (Bioprecisa) empregada para pesar $0,15 \mathrm{~g}$ da tripsina para o preparo da solução.

C. Dentes imersos em recipientes de vidro contendo $0,15 \mathrm{~g}$ de tripsina adicionada a $5 \mathrm{~mL}$ de água destilada, resultando numa concentração de $0,03 \mathrm{~g} / \mathrm{mL}$.

D. Lavagem do espécime com solução tampão de cacodilato a 0,1M.

E. Fixação dos espécimes em solução de Karnovsky modificada.

F. Confeç̧ão de sulco a $3 \mathrm{~mm}$ do ápice radicular com disco de carborundum e motor de baixa rotação.

G. Desidratação dos ápices radiculares em soluções crescentes de álcool a 70, 95 e $100 \%$, realizando quatro trocas de cada solução a cada 15 minutos. 


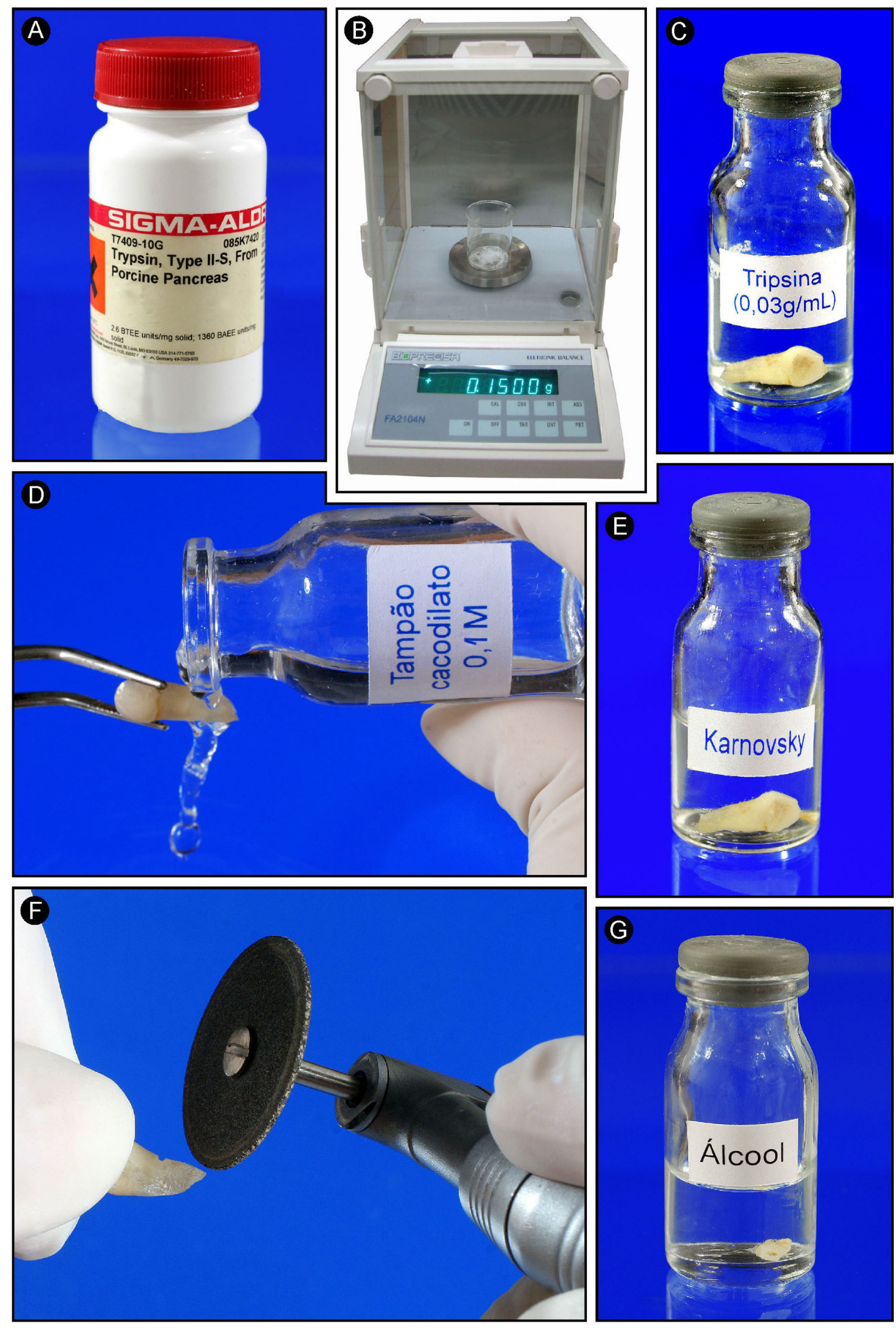




\subsection{Processamento para Microscopia Eletrônica de Varredura}

Os ápices radiculares ( $3 \mathrm{~mm}$ apicais) foram desidratados em solução crescente de etanol a 70, 95 e 100\% (Figura 1G), sendo realizadas quatro trocas de cada solução a cada 15 minutos. Os espécimes foram submetidos à desidratação com $\mathrm{CO}_{2}$ no ponto crítico em aparelho Bal-Tec CPD 030 (Fürstentum, Liechtenstein) (Figuras 2A e 2B). Em seguida, os espécimes foram cobertos com

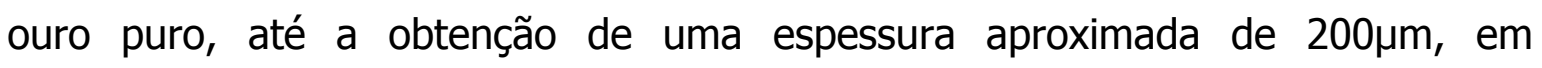
metalizador Emitech K650 Spitter Coater (London, England) (Figuras 2C e 2D). Após metalização (Figura 2E), os espécimes foram avaliados em Microscópio Eletrônico de Varredura DSM 940A (Zeiss, Oberkochen, Germany) (Figuras 2F, 2 G e $2 \mathrm{H})$. 
Figura 2 - Preparo dos espécimes para análise em microscopia eletrônica de varredura

A. Ápices radiculares inseridos no dispositivo para serem levados à secagem no ponto crítico.

B. Dispositivo colocado no aparelho Bal-Tec CPD 030 para desidratação com $\mathrm{CO}_{2}$ no ponto crítico.

C e D. Espécimes montados em "stubs" para serem submetidos à metalização em aparelho Emitech K650 Spitter Coater até obter uma espessura de $200 \mu \mathrm{m}$.

E. Espécime metalizado no "stub" armazenado em uma gaveta própria até o momento da análise.

F. "Stub" fixado no "porta-stub" contido no interior do microscópio eletrônico de varredura.

G. Microscópio eletrônico de varredura (DSM 940A).

H. Obtenção das eletromicrografias dos ápices radiculares de dentes decíduos, evidenciando ou não a presença de microrganismos sob a forma de biofilme. 

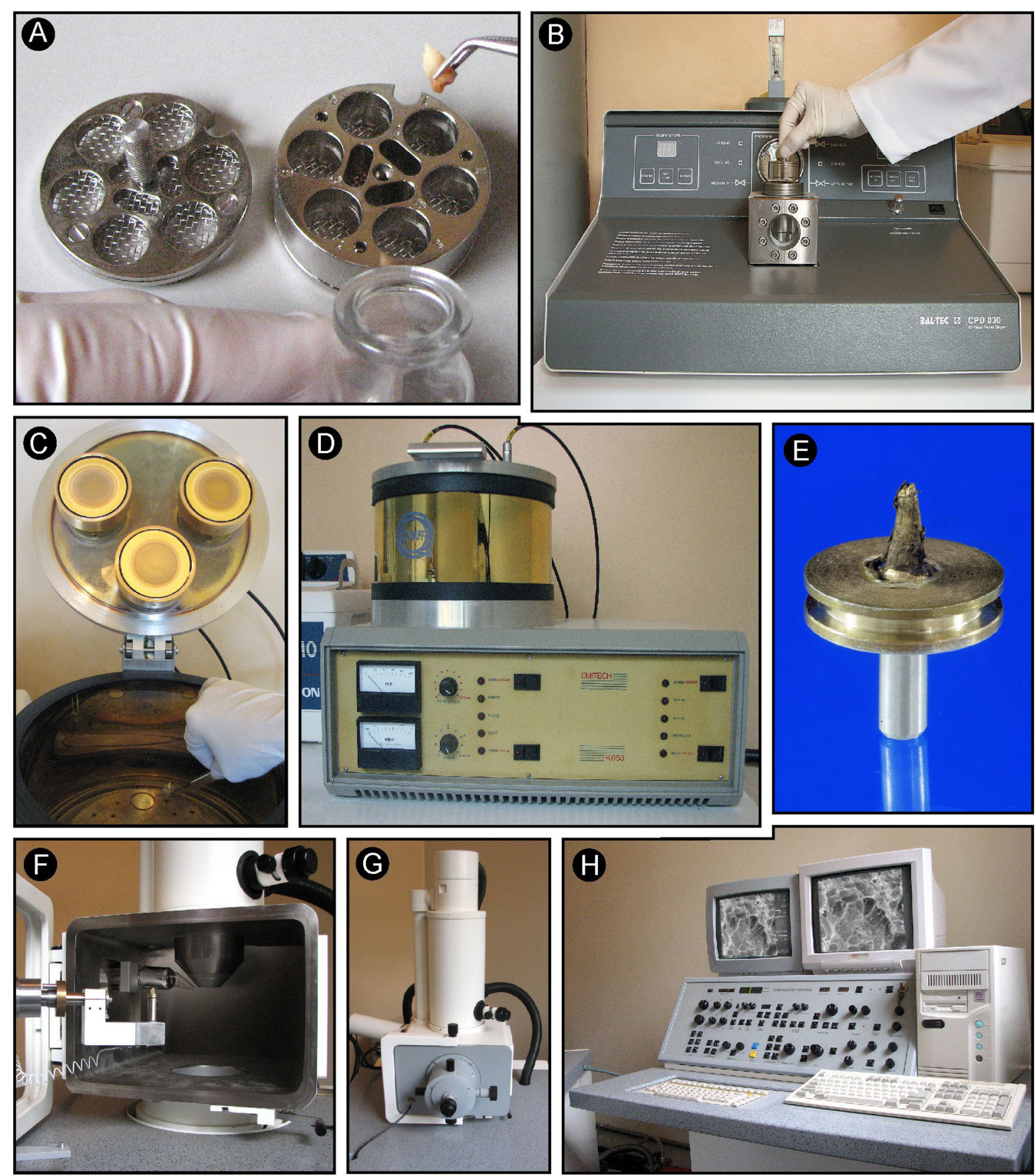


\subsection{Análise das amostras}

Durante a análise das amostras, inicialmente foi utilizado um aumento de 50 vezes para a localização da porção apical da raiz, permitindo uma visão geral da morfologia da superfície radicular apical e áreas adjacentes.

A área do forame apical principal foi observada com aumentos de 50, 100, 200, 350 e 500 vezes, tendo a região apical como referência.

Aumentos maiores (1000, 2000 e 3000 vezes) foram utilizados para identificar a presença de fibras e áreas de reabsorção radicular (cemento e dentina). A prevalência de presença de fibras e áreas de reabsorção, nos diferentes grupos experimentais, foi registrada em termos de porcentagem, sendo efetuadas eletromicrografias de espécimes representativos dos resultados obtidos. 
4 Resultados 


\section{Resultados}

GRUPO I - DENTES DECÍDUOS PORTADORES DE VITALIDADE PULPAR

A tabela 2 apresenta a caracterização das amostras dos dentes decíduos portadores de vitalidade pulpar (Grupo I).

Tabela 2 - Caracterização das amostras dos dentes decíduos portadores de vitalidade pulpar

\begin{tabular}{clcl}
\hline Dente & Motivo da Exodontia & $\begin{array}{c}\text { Idade } \\
\text { (anos) }\end{array}$ & Sexo \\
\hline Incisivo central (71) & Retenção prolongada & 06 & Feminino \\
Incisivo central (81) & Retenção prolongada & 07 & Feminino \\
Molar (84) & Retenção prolongada & 07 & Masculino \\
Incisivo central (71) & Retenção prolongada & 07 & Masculino \\
Incisivo central (51) & Retenção prolongada & 06 & Masculino \\
\hline
\end{tabular}

Nas raízes avaliadas no grupo I (100\%), pôde-se observar que a superfície cementária encontrava-se recoberta por intensa quantidade de fibras colágenas, dispostas nos mais variados sentidos (Figura 3). Remanescentes do ligamento periodontal e fibras colágenas partiam da superfície apical em delicados ou em espessos feixes entrelaçados entre si, indicando a normalidade da região, como evidenciado nas figuras (3D e E). 
Figura 3

\section{GRUPO I - DENTES DECÍDUOS PORTADORES DE VITALIDADE PULPAR}

A e B. Visão panorâmica do ápice radicular íntegro. A, barra $=400 \mu m$; B, barra $=400 \mu \mathrm{m}$.

C. Maior aumento do ápice radicular recoberto por remanescentes do ligamento periodontal. Barra $=200 \mu \mathrm{m}$.

D e E. Entrelaçamento de feixes de fibras colágenas dispostas sobre a superfície cementária, demonstrando a normalidade do tecido apical, em maiores aumentos. $D$, barra $=20 \mu \mathrm{m} ; \mathrm{E}$, barra $=10 \mu \mathrm{m}$.

F. Radiografia do dente decíduo 84 , com retenção prolongada e integridade da lâmina dura. 

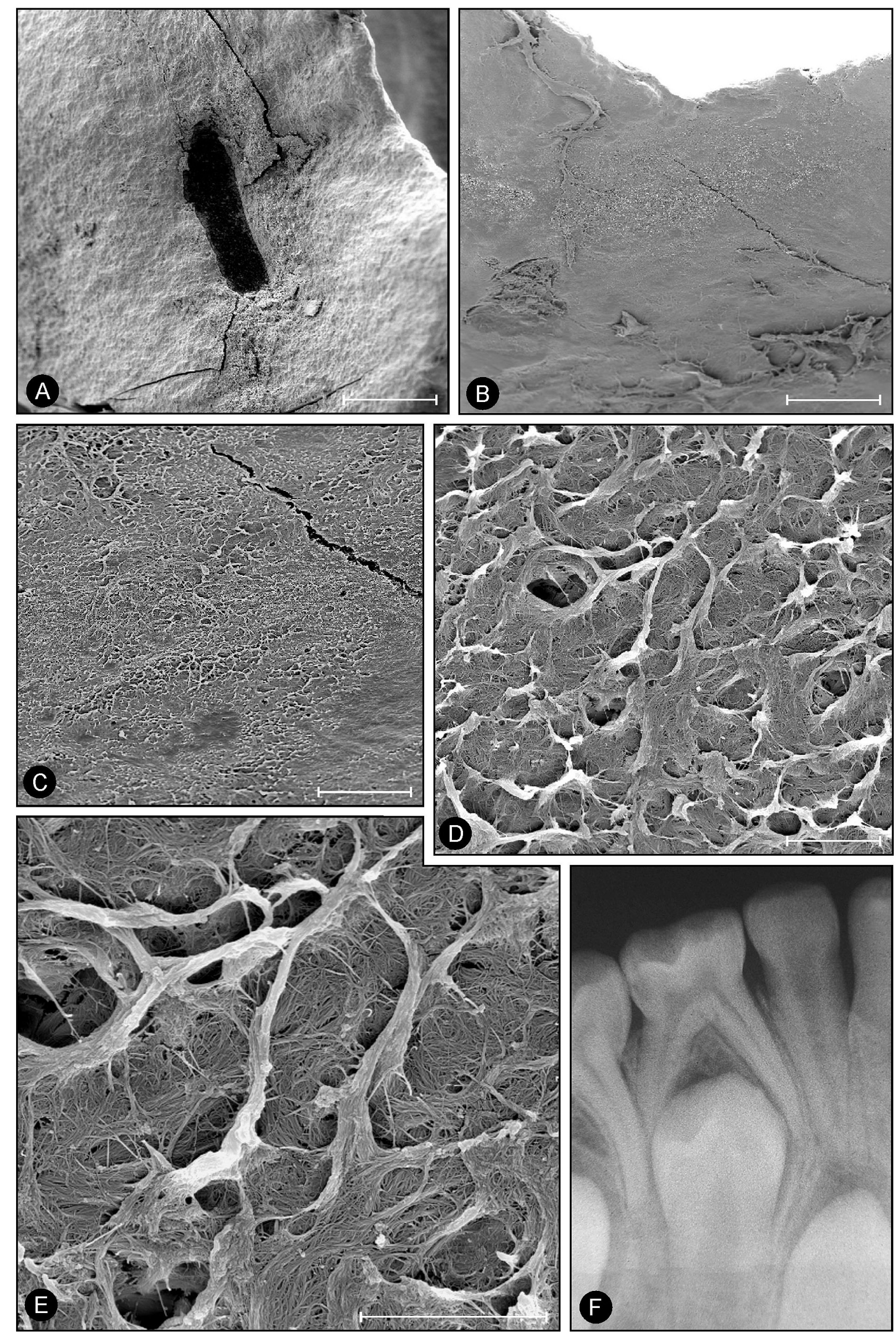
GRUPO II - DENTES DECÍDUOS PORTADORES DE NECROSE PULPAR, SEM LESÃO PERIAPICAL VISÍVEL RADIOGRAFICAMENTE

A tabela 3 apresenta a caracterização das amostras dos dentes decíduos portadores de necrose pulpar, sem lesão periapical visível radiograficamente (grupo II).

Tabela 3 - Caracterização das amostras dos dentes decíduos portadores de necrose pulpar, sem lesão periapical visível radiograficamente

\begin{tabular}{clcl}
\hline Dente & Motivo da Exodontia & $\begin{array}{c}\text { Idade } \\
\text { (anos) }\end{array}$ & Sexo \\
\hline Molar (65) & Extensa destruição coronária & 05 & Masculino \\
Incisivo lateral (52) & Extensa destruição coronária & 05 & Masculino \\
Incisivo central (61) & Extensa destruição coronária & 05 & Masculino \\
Molar (64) & Extensa destruição coronária & 05 & Feminino \\
Molar (85) & Extensa destruição coronária & 08 & Masculino \\
Molar (64) & Extensa destruição coronária & 08 & Masculino \\
\hline
\end{tabular}

Em todas as seis raízes avaliadas no grupo II (100\%), pôde-se observar que a superfície cementária encontrava-se recoberta por grande quantidade de fibras colágenas, dispostas nos mais variados sentidos. O ápice radicular mostrava aspectos anatômicos de normalidade, na região próxima ao forame apical, bem como distante da mesma (Figura 4).

Adjacente ao forame, observou-se a presença de fibras colágenas dispostas em feixes e em diferentes sentidos, as quais recobriam toda a superfície cementária (Figura 4C a F). 
Figura 4

\section{GRUPO II - DENTES DECÍDUOS PORTADORES DE NECROSE PULPAR, SEM LESÃO PERIAPICAL VISÍVEL RADIOGRAFICAMENTE}

A. Ápice radicular com aspectos anatômicos de normalidade. Forame apical. Barra $=400 \mu \mathrm{m}$.

B. Presença de fibras colágenas recobrindo a superfície do cemento apical. Barra $=100 \mu \mathrm{m}$.

C e D. Presença de fibras colágenas recobrindo toda a superfície cementária apical. C, barra $=20 \mu \mathrm{m} ; \mathrm{D}$, barra $=10 \mu \mathrm{m}$.

E e F. Em maior aumento, superfície apical evidenciando entrelaçamento das fibras colágenas. $E$, barra $=10 \mu \mathrm{m} ; \mathrm{F}$, barra $=10 \mu \mathrm{m}$. 

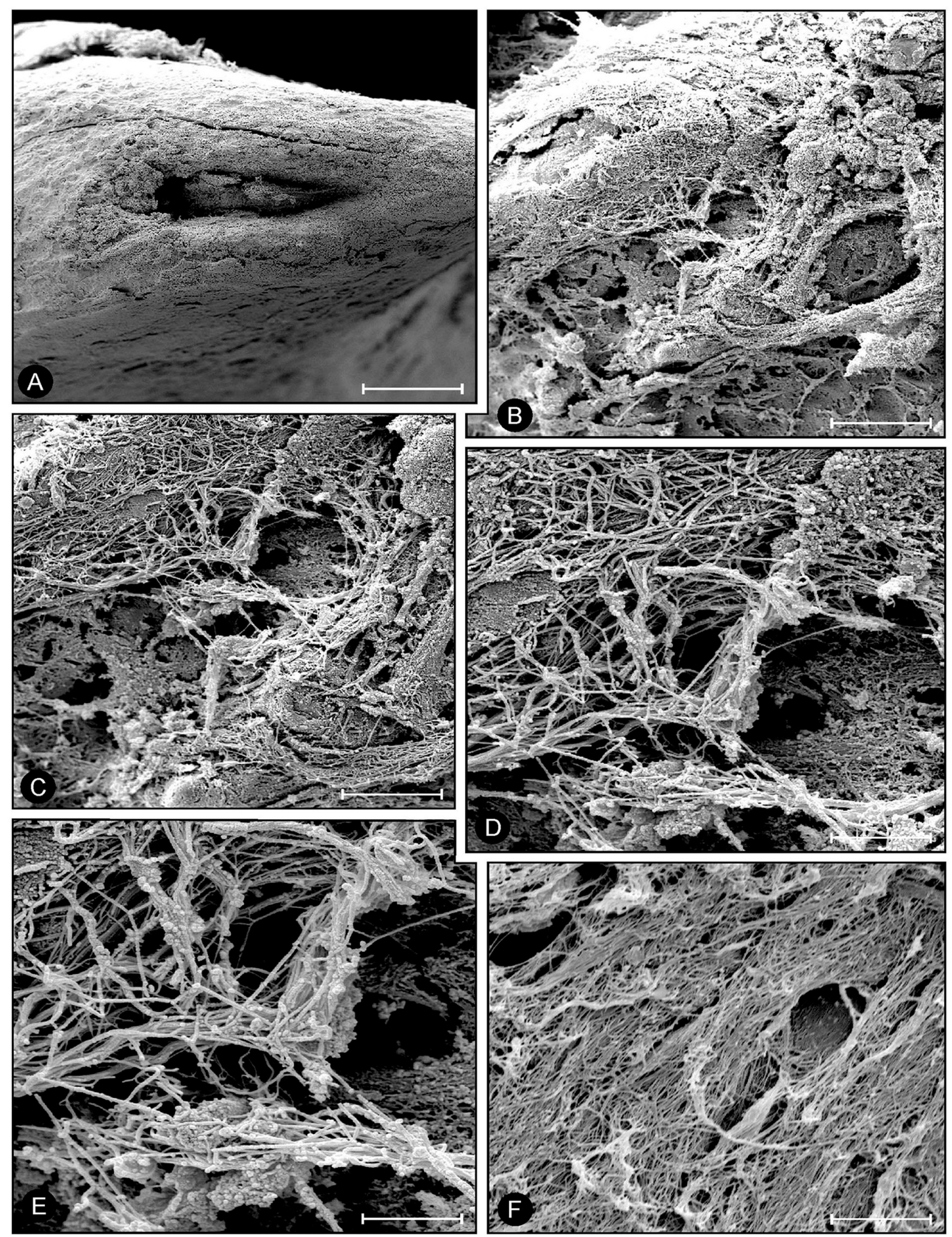
GRUPO III - DENTES DECÍDUOS PORTADORES DE NECROSE PULPAR E NÍTIDA LESÃO PERIAPICAL VISÍVEL RADIOGRAFICAMENTE

A caracterização das amostras dos dentes decíduos portadores de necrose pulpar e nítida lesão periapical visível radiograficamente está apresentada na tabela 4.

Tabela 4 - Caracterização das amostras dos dentes decíduos portadores de necrose pulpar e nítida lesão periapical visível radiograficamente

\begin{tabular}{cccc}
\hline Dente & Motivo da Exodontia & $\begin{array}{c}\text { Idade } \\
\text { (anos) }\end{array}$ & Sexo \\
\hline Molar (84) & Extensa destruição coronária & 07 & Masculino \\
Molar (74) & Extensa destruição coronária & 05 & Feminino \\
Molar (85) & Extensa destruição coronária & 06 & Masculino \\
Incisivo lateral (52) & Extensa destruição coronária & 06 & Feminino \\
Molar (55) & Extensa destruição coronária & 06 & Masculino \\
Molar (55) & Extensa destruição coronária & 05 & Feminino \\
Incisivo central (51) & Extensa destruição coronária & 05 & Feminino \\
Molar (74) & Extensa destruição coronária & 05 & Masculino \\
\hline
\end{tabular}

Em todos os oito dentes decíduos com necrose pulpar e lesão periapical visível radiograficamente $(100 \%)$, a superfície do ápice radicular apresentava ausência de fibras colágenas e extensas áreas de reabsorção na região próxima ao forame apical, atingindo às vezes quase toda a sua extensão. Essas áreas superficiais de reabsorção cementária com diferentes profundidades, estavam distribuídas em toda a região (Figuras 5 e 6) e em 2 espécimes (25\%) com exposição de túbulos dentinários (Figura 6B a F). 
Figura 5

GRUPO III - DENTES DECÍDUOS PORTADORES DE NECROSE PULPAR E NÍTIDA LESÃOPERIAPICAL VISÍVEL RADIOGRAFICAMENTE

A. Visão panorâmica do ápice radicular. Forame apical. Barra $=400 \mu m$.

B. Maior aumento da Figura A, evidenciando ausência de fibras e área de reabsorção do cemento apical, adjacente ao forame. Barra=100 $\mu \mathrm{m}$.

C e D. Maior aumento da figura B evidenciando a ausência de fibras e presença de extensas áreas de reabsorção do cemento apical. C, barra $=40 \mu \mathrm{m} ; \mathrm{D}$, barra $=20 \mu \mathrm{m}$.

E. Maior aumento da figura anterior, evidenciando áreas de reabsorção cementária apical, de diferentes tamanhos e profundidade. Ausência total de fibras colágenas. Barra $=10 \mu \mathrm{m}$.

F. Radiografia do dente decíduo 54, com necrose pulpar e nítida lesão periapical crônica, visível radiograficamente. 

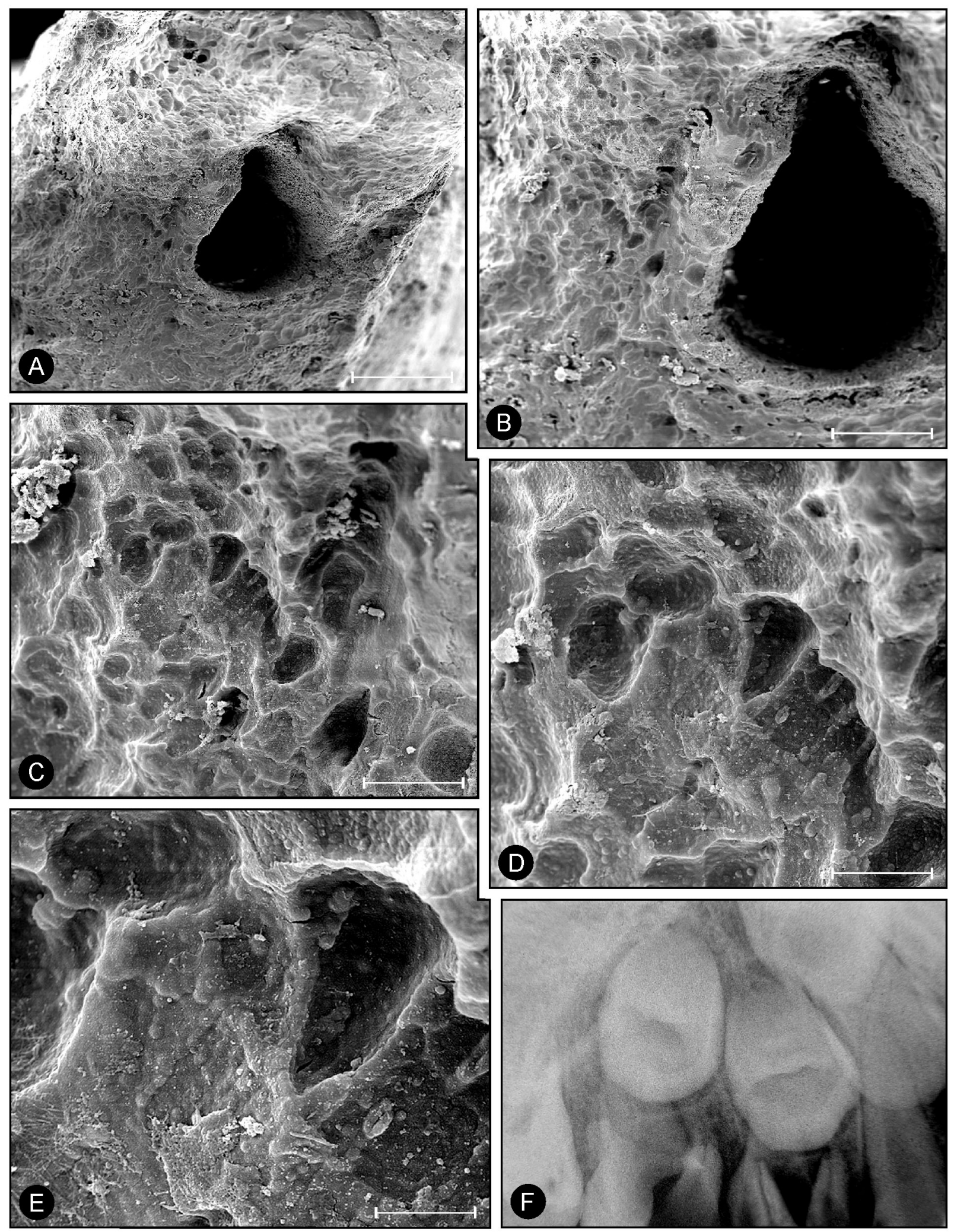
Figura 6

\section{GRUPO III - DENTES DECÍDUOS PORTADORES DE NECROSE PULPAR E NÍTIDA LESÃOPERIAPICAL VISÍVEL RADIOGRAFICAMENTE}

A. Região próxima ao forame apical evidenciando ausência de fibras e extensa área de reabsorção cementária apical. Barra=100 $\mu \mathrm{m}$.

B, C, D, E e F. Maiores aumentos da Figura A evidenciando as áreas de reabsorção com diferentes tamanhos e profundidades, expondo túbulos dentinários. $B$, barra $=40 \mu \mathrm{m} ; \mathrm{C}$, barra $=40 \mu \mathrm{m} ; \mathrm{D}$, barra $=40 \mu \mathrm{m} ; \mathrm{E}$, barra $=20 \mu \mathrm{m} ; \mathrm{F}$, barra $=10 \mu \mathrm{m}$. 

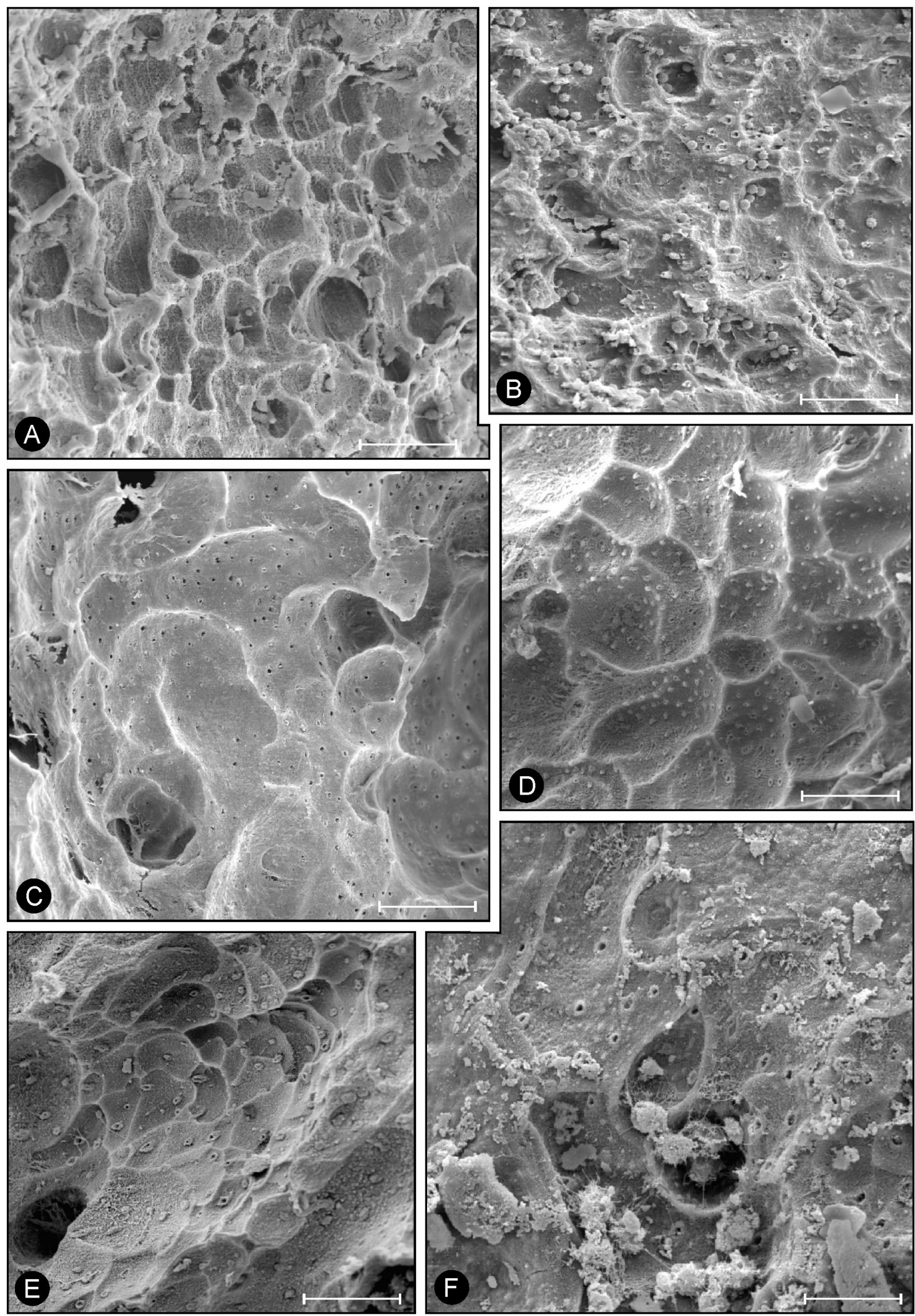


\section{Discussão}

\section{Da Metodologia}

Vários estudos têm sido efetuados utilizando a microscopia eletrônica de varredura (MEV) para avaliar os ápices radiculares de dentes permanentes (Auyeng et al., 1988; Delzangles, 1989; Malueg et al., 1995; Lomçali et al., 1996; Ferllini Filho, 1997; Siqueira e Lopes, 2001; Leonardo et al., 2002; Vier e Figueiredo, 2002), tendo em vista que essa técnica permite a observação de detalhes morfológicos. No entanto, consultando a literatura específica, não foram encontrados trabalhos que avaliassem em MEV, especificamente a morfologia de ápices radiculares de dentes decíduos.

Quanto à preparação das amostras após a extração dental, embora alguns autores tenham utilizado o hipoclorito de sódio a 2,5\% (Delzangles, 1989; Vier e Figueiredo, 2002) ou o hipoclorito de sódio a 10\% (Furusawa e Asai, 2002), em nosso estudo os espécimes foram acondicionados em recipientes de vidro contendo solução de $0,15 \mathrm{~g}$ de tripsina (Sigma Chemical Co., St. Louis, MO) em água destilada, com concentração final de $0,03 \mathrm{~g} / \mathrm{mL}$, durante 20 minutos. A opção por esta solução foi devido à sua eficácia na remoção dos resíduos de matéria orgânica depositados sobre a superfície radicular, possibilitando uma melhor observação das estruturas dessa região (Leonardo et al., 2002; Ferreira et al., 2004).

Para a fixação tecidual, a escolha pela solução de Karnovsky modificada foi devido à sua baixa porcentagem de formaldeído, o que permitiu uma estabilização mais rápida da mesma, evitando danos aos tecidos. Por outro lado, a presença do 
glutaraldeído nessa solução possibilita uma fixação tecidual mais estável e mais lenta. A presença de cacodilato de sódio visou permitir uma maior vida útil à solução fixadora, bem como evitar o crescimento bacteriano (Karnovsky, 1965; Bozzolla e Russel, 1992; Bancroft e Stevens, 1996).

Como na grande maioria dos trabalhos que empregaram a MEV (Delzangles, 1988; Lomçali et al., 1996; Leonardo et al., 2002; Vier e Figueiredo, 2002; Furusawa e Asai, 2002), os espécimes receberam trocas sucessivas de solução crescente de etanol (70, 95 e 100\%) sendo, posteriormente, desidratados com $\mathrm{CO}_{2}$ no ponto crítico, evitando a secagem ao meio ambiente e danos aos tecidos que, nessas condições, sofrem colapso, achatamento ou contrações, devido à passagem de ar ou de água entre os tecidos, criando uma força de tensão superficial elevada (Bozzolla e Russel, 1992). Molven et al. (1991), Lomçali et al. (1996) e Sen et al. (1995) também optaram pela lavagem em série crescente de etanol e uso do ponto crítico para a secagem e desidratação dos espécimes, com o objetivo de verificar a integridade dos tecidos radiculares (cemento e dentina), evitando a formação de trincas ou rachaduras nos mesmos.

No presente estudo, os espécimes foram metalizados com liga de ouro, na espessura de $200 \mu \mathrm{m}$, em função de ser metal um bom condutor (Bozzolla e Russel, 1992). Em relação à análise das amostras, o aumento de 50x possibilitou a localização inicial do forame apical e, a partir desta referência, pôde-se observar em maiores aumentos (de 200 a 3000 vezes) a presença de fibras colágenas e as áreas de reabsorção radicular na região apical, o que também foi observado por Malueg et al. (1996), Lomçali et al. (1996), Ferllini Filho (1999) e Leonardo et al. (2002). 
Os resultados do presente estudo nos permitiram observar que essa metodologia mostrou-se útil para avaliação de alterações morfológicas na superfície externa de ápices radiculares em dentes decíduos de humanos, à semelhança do que ocorre com dentes permanentes.

\section{Dos Resultados}

Sabe-se que o cemento é um tecido dental mineralizado que recobre as raízes de dentes humanos, cuja função é prover um meio para ancoragem das fibras colágenas que ligam os dentes às estruturas vizinhas (Bhaskar, 1989). O conhecimento dessas estruturas é de extrema importância para o tratamento endodôntico, já que é no ligamento periodontal que inicialmente se desenvolve o processo inflamatório, desencadeando as alterações patológicas periapicais (Leonardo e Holland, 1974; Lamers et al., 1980; Bhaskar, 1989).

De acordo com os resultados do presente estudo, observou-se que as fibras colágenas estavam intactas em todos os dentes (100\%) dos grupos I (vitalidade pulpar) e II (necrose pulpar sem lesão periapical). No entanto, em todos os dentes do grupo III (necrose pulpar e lesão periapical) havia ausência de fibras, evidenciando que o processo inflamatório e a infecção se localizam não apenas na luz do canal radicular, mas também na região apical, atingindo a superfície externa da raiz.

Esses resultados, em dentes decíduos, são discordantes dos relatados por Malueg (1996) e Lomçali et al. (1996), que observaram a presença de áreas de reabsorção cementária na região apical de dentes permanentes portadores de vitalidade pulpar. 
A infecção extra-radicular em geral ocorre como resultado da infecção do tecido pulpar, seguida pela necrose tecidual e acometimento da região apical, com instalação de uma lesão periapical crônica visível radiograficamente. Em dentes permanentes, esse processo patológico inflamatório e infeccioso resulta na reabsorção de cemento e, algumas vezes, de dentina, atingindo a superfície radicular externa. A reabsorção radicular apical histologicamente evidente não pode ser visualizada radiograficamente em seu estágio inicial (Walton e Garnick, 1986).

Com relação ao grupo III (dentes com necrose pulpar e lesão periapical), os resultados do nosso estudo, em dentes decíduos, onde observamos ausência de fibras e presença de áreas de reabsorção cementária em 100\% dos dentes, são concordantes com os achados de Malueg et al. (1996), Gutiérrez et al. (1999) Leonardo et al. (2002), Vier e Figueiredo (2002), Noiri et al. (2002) e Ferreira et al. (2004). Esses autores avaliaram, por meio de MEV, dentes permanentes extraídos, observando ausência de fibras e presença de áreas de reabsorção cementária na superfície apical externa.

Dessa maneira, observamos que o uso da MEV mostrou-se eficaz no estudo das alterações morfológicas e estruturais na superfície radicular externa, auxiliando no entendimento das patologias pulpares e periapicais, em dentes decíduos.

Nossos resultados possibilitam estabelecer orientações quanto à técnica e ao prognóstico do tratamento endodôntico em dentes decíduos portadores de diferentes graus de patologia pulpar e periapical. Em dentes decíduos portadores de vitalidade pulpar ou com necrose pulpar sem lesão periapical, a preocupação 
do cirurgião-dentista pode se limitar à remoção do conteúdo do canal radicular, irrigação com solução bactericida e obturação dos canais radiculares com material biocompatível e reabsorvível, tendo em vista que o ápice radicular, nesses casos, não apresenta alterações morfológicas, estando as fibras e o cemento radicular preservados, como observado no presente estudo.

Por outro lado, no caso de dentes decíduos com necrose pulpar e lesão periapical crônica visível radiograficamente, alterações morfológicas ocorrem na região do ápice radicular com destruição das fibras e reabsorção cementária de tamanhos variados. Esses sítios servem como nichos para o desenvolvimento de microrganismos sob a forma de biofilme. Assim, frente a essa situação torna-se de fundamental importância, além dos procedimentos técnicos citados acima, empregar soluções irrigadoras mais enérgicas e utilizar curativo de demora entre sessões, com o intuito de combater a infecção extra-radicular. Consequentemente, isso irá auxiliar no reparo das fibras lesadas e das áreas de reabsorção. Estudos adicionais são necessários, a fim de avaliar a eficácia de diferentes técnicas de tratamento e materiais que permitam o reparo das áreas da superfície radicular com alterações morfológicas, de origem patológica, em dentes decíduos. 


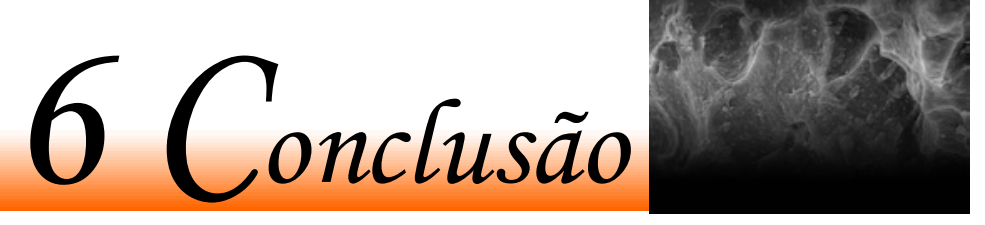




\section{Conclusão}

Com base na metodologia empregada (microscopia eletrônica de varredura) e nos resultados obtidos, pudemos concluir que:

- Nos ápices radiculares de dentes decíduos com vitalidade pulpar (Grupo I) e com necrose pulpar sem lesão periapical visível radiograficamente (Grupo II) observou-se presença de fibras e ausência de áreas de reabsorção em todos os casos.

- Em 100\% das amostras dos dentes decíduos portadores de necrose pulpar e lesão periapical visível radiograficamente (Grupo III) observou-se ausência de fibras e extensas áreas de reabsorção. 
Referências 


\section{RefERÊNCIAS}

1. Assed S. Odontopediatria: Bases científicas para a prática clínica. São Paulo: Artes Médicas, 2005.

2. Auyeung L, Bouwasma OJ, Polson AM. Periodontal fiber attachment and apical root resorption. Endod Dent Traumatol 1988; 4:219-25.

3. Bhaskar SN. Histologia e Embriologia Oral de Orban. 10a ed. Artes Médicas. 1989.

4. Bancroft JD, Stevens A. Theory and practice of histological techniques. 4.ed. London, Churchill Livingstone,1996.

5. Bilgin E, Gürgan CA, Nejat Arpak, Bostanci HS, Güven K. Morphological changes in diseased cementum layers: a scanning electron microscopy study. Calcif Tissue Int 2004; 74:476-85.

6. Bozzola JJ, Russell LD. Electron microscopy. Principles and techniques for biologists. Boston, Jones and Bartlett Publishers, 1992.

7. Calas P, Rochd T, Michel G. In vitro attachment of streptococcus sanguis to the dentin of the root canal. J Endod 1994; 20:71-74.

8. Cholia SS, Wilson PHR, Makdissi J. Multiple idiopathic external apical root resorption: report of four cases. Dentomaxillofacial radiology 2005; 34:240-46.

9. Consolaro A. Reabsorções Dentárias nas especialidades clínicas. 2a ed. Maringá, PR: Dental Press, 2005. 616p. 
10. Delzangles B. Scanning electron microscopic study of apical and intracanal resorption. J endod 1989; 15:281-85.

11. Faltin RM, Faltin K, Sander FG, Arana-Chavez VE. Ultrastructure of cementum and periodontal ligament after continuous intrusion in humans: a transmission electron microscopy study. Eur J Orthodont 2001; 23:35-49.

12. Fellini Filho J. Estudo radiográfico e microscópico das reabsorções radiculares na presença de periodontites apicais crônicas (Microscopia ótica e eletrônica de varredura). Bauru, 1999. Tese [Doutorado] - Faculdade de Odontologia de Bauru, Universidade de São Paulo.

13. Ferreira FBA, Ferreira AL, Gomes BPFA, Souza-Filho FJ. Resolution of persistent periapical infection by endodontic surgery. Int Endod J 2004; $37: 61-9$.

14. Furusawa M, Asai Y. SEM observations of resected root canals ends following apicectomy. Bull Tokyo Dent Coll 2002; 43:7-12.

15. Fuss Z, Tsesis I, Lin S. Root resorption - diagnosis, classification and treatment choices based on stimulation factors. Dent Traumatol 2003; 19: 175-182.

16. Gutiérrez JH, Brizuela C, Villota E. Human teeth with periapical pathosis after overinstrumentation na overfiling of root canals: a scanning electron microscopy study. Int Endod J 1999; 32:40-48.

17. Karnovsky MJ. A formaldehyde-glutaraldehyde fixative of high osmolarity for use in electron microscopic. J Cell Biol 1965; 27:5 (ESE Abstract). 
18. Lamers $\mathrm{AC}$, Mullen $\mathrm{PJ}$, Simon $\mathrm{M}$. Tissue reaction to sodium hypochlorite and iodine potassium iodide under clinical condition in monkey teeth. J Endod $1980 ; 6(10): 788-92$.

19. Laux M, Abbott PV, Pajarola G, Nair P. Apical inflammatory root resorption: a correlative radiographic and histological assessment. Int Endod J 2000; 33:483-93.

20. Leonardo MR. Endoddontia: Tratamento de canais radiculares - princípios técnicos e biológicos. São Paulo: Artes Médicas, 2005.

21. Leonardo MR, Rossi MA, Silva LAB, Ito IY, Bonifácio KC. EM evaluation of bacterial biofilm and microorganisms on the apical external root surface of human teeth. J Endod 2002; 28(12):815-8.

22. Leonardo MR, Holland R. Healing process after vital pulp extirpation and immediate root canal feeling with calcium hydroxide. Histological study in human teeth. Rev Fac Odont Araçatuba 1974; 3(2):159-65.

23. Lomçali G, Sem BH, Çankaya H. Scanning electron microscopic observations of apical root surfaces of teeth with apical periodontitis. Endod Dent Traumatol 1996;12(2):70-6.

24. Lyroudia KM, Dourou VI, Pantelidou OC, Lambriaanidis T, Pitas IK. Internal root resorption studied by radiography, stereomicroscope, scanning electron microscope, and computerized 3D reconstructive method. Dent Traumatol $2002 ; 189: 148-52$. 
25. Malueg LA, Wilcox LR, Johnson W. Examination of external apical root resorption with scanning electron microscopy. Oral Surg Oral Med Oral Pathol 1996; 82:89-93.

26. Molven O, Olsen I, Kereses K. Scanning electron microscopy of bacteria in the apical part of root canals in permanent teeth with perioapical lesions. Endod Dent Traumatol 1991; 7(5):226-9.

27. Morfis AS, Karas S, Georgopoulou M, Kerani M, Proventzas F. Scanning electron microscopic study of the apices of human permanent teeth. Int Endod J 1992, 25:40 (ESE abstract).

28. Noiri Y, Ehara A, Kawahara T, Takemura N, Ebisu S. Participation of bacterial biofilms in refractory and chronic periapical periodontitis. J Endod 2002; 28(10):679-83.

29. Perez F, Rochd T, Lodter JP, Calas P, Michel G. In vitro study of the penetration of three bacterial strains into root dentin. Oral Surg Oral Med Oral Pathol 1993; 76(1):97-103.

30. Sen BH, Piskin B, Demirci T. Observation of bacteria and fungi in infected canals and dentinal tubules by SEM. Endod. Dent Traumatol 1995;11(1):6-9.

31. Sen BH, Safavi KE, Spangerg LSW. Growth patterns of Candida albicans in relation to radicular dentin. Oral Surg Oral Med Oral Pathol 1997; 84:68-73.

32. Siqueira JF, Lopes HP. Bacteria on the apical root surfaces of untreated teeth with periradicular lesions: a scanning electron microscopy study. Int Endod J $2001 ; 34: 216-20$. 
33. Vier FV, Figueiredo JAP. Prevalence of different periapical lesions associated with human teeth and their correlation with the presence and extension of apical external root resorption. Int Endod J 2002; 35:710-19.

34. Yawaka Y, Osani M, Akiyama A, Ninomiya R, Oguchi H. Histological study of deposited cementum in human deciduous teeth with pathological root resorption. Ann Anat 2003; 185:335-41.

35. Tronstad L. Root resorption, etiology, terminology, and clinical manifestation. Endodontics and Dental traumatology 1988; 4:241-52.

36. Tronstad L, Barnett F, Riso K, Slots J. Extraradicular endodontic infections. Endod Dent Traumatol 1987; 3(2):86-90.

37. Tronstad L, Barnett F, Cervone F. Periapical bacterial plaque in teeth refractory to endodontic treatment. Endod Dent Traumatol 1990; 6(2):73-7.

38. Walton RE, Garnick JJ. The histology of periapical Inflammatory lesions in permanent molars in monkeys. J Endod 1986; 12:49-53. 
Anexo 


\title{
Anexo A- Aprovação do Comitê de Ética
}

\author{
UNIVERSIDADE DE SÃO PAULO \\ FACULDADE DE ODONTOLOGIA DE RIBEIRÃO PRETO \\ COMITÊ DE ÉTICA EM PESQUISA
}

Avenida do Café. s/n ${ }^{\circ}$ - Telefone: (016) 3602-3963

14040-904 - Ribeirao Preto-SP-Brasil

Fax: (016) 3633-0999

OF.CEP/419/FORP/29112006

Prezado(a) Prcfecsoria),

Ref.; Processo n. 2006.1.1310.58.2

Caae n.0069.0.138.000-06

De ordem da Senhora Coordenadora do Comitê de Ética em Pesquisa desta Faculdade, informamos que o referido Comitê, em sua $73^{a}$ Sessão realizada no dia 29 de novembro de 2006, deliberou aprovar o Projeto de Pesquisa envolvendo seres humanos intitulado: "MEV - Avaliação morfológica do ápice radicular em dentes decíduos de humanos, com e sem lesão periapical visivel radiograficamente", a ser desenvolvido por Vossa Senhoria na Faculdade de Odontologia de Ribeirão Preto, devendo o atestado para publicação final ser expedido pelo Comitê de Ética em Pesquisa, após a entrega e aprovação do Relatório Final pelo referido Comitê.

Na oportunidade, lembramos da necessidace de entregar na Secretaria do Comitê, com o formulário preenchido pelo pesquisador responsável, o Relatório Final até o dia $\mathbf{3 0}$ de novembro de 2007.

Atenciosamente,

\section{Cauce Defle}

Secretária do Comitê de Ética em Pesquisa

Ilmà. Sra.

Profa. Dra. LÉA ASSED BEZERRA DA SILVA

Professoa Titular do Departamento de Clínica Infantil, Odontologia Preventiva e Social FORP/USP 


\section{AUTORIZAÇÃO PARA REPRODUÇÃO}

Autorizo a reprodução e/ou divulgação total ou parcial da presente obra, por qualquer meio convencional ou eletrônico, desde que citada a fonte.

Patrícia Motta Fernandes

Universidade de São Paulo

Faculdade de Odontologia de Ribeirão Preto

Departamento de Clínica Infantil, Odontologia Preventiva e Social

Ribeirão Preto/junho de 2007

Avenida do Café s/n CEP 14040-904

e-mail: pathymotta@hotmail.com 